\title{
LA CONSTITUCIÓN DE 1925: (OBRA PREMIADA POR LA FACULTAD DE CIENCIAS JURÍDICAS Y SOCIALES EN EL CERTAMEN BIENAL DE 1926-1927)*
}

* José Guillermo Guerra. La Constitución de 1925 : (obra premiada por la Facultad de Ciencias Jurídicas y Sociales en el Certamen Bienal de 1926-1927). Establecimientos Gráficos "Balcells y Co.", Santiago de Chile. 1929. 


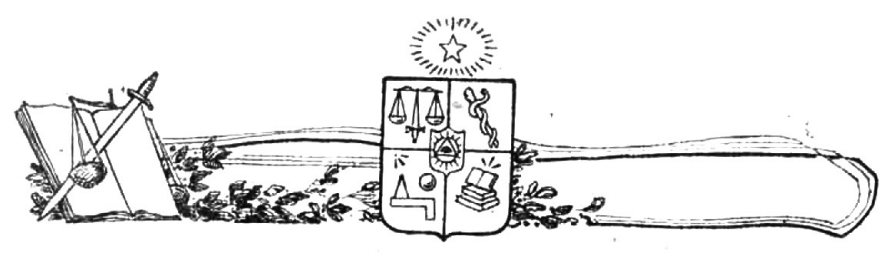

\section{PRÓLOGO}

La reforma constitucional realizada en Chile el año 1925 es para nosotros especialmente grata. Coneurrimos a ella con modesta labor, pero con la más profunda convicción de que era indispensable y correspondía a las necesidades y conveniencias de la República.

Fuímos decididamente adictos al movimiento de depuración política iniciado el 5 de Septiembre de 1924, y, comprendiendo que él tendría que producir necesariamente un cambio considerable en las instituciones fundamentales de Chile, solicitamos la hospitalidad del diario La Nación de Santiago, para ir dando a luz, en forma desaliñada y sin pretensiones, $y$ firmados con un seudónimo, una serie de artículos sobre la Reforma Constitucional, que alcanzaron a ser treinta y aparecieron desde el 22 de Febrero hasta el 25 de Junio de 1925.

En aquellos artículos improvisados al correr de la pluma, nada propusimos que fuera de nuestra propia cosecha. Nos limitamos a exponer lo que habíamos oído mil veces a centenares de personas conscientes y bien intencionadas, a resumir en breves términos las aspiraciones de la opinión pública independiente, de aquella parte de los habitantes de Chile que no habían medrado núnca con la política, sino que habían sido siempre víctimas de ella.

De esos artículos hemos formado un folleto que apareció en el mes de Septiembre del año pasado, icon el título de Temas Constitucionales, y que, en buenos términos, es el verdadeno Prólogo del libro que ahora sometemos al estudio y a la benevolencia de nuestros compatriotas. 
Cuando íbamos a medio camino en la publicación de esos artículos, tuvimos el honor de ser incluídos en la lista de ciudadanos que el Presidente Alessandri llamó, por decreto N.? 1422, del 7 de Abril de 1925, para formar la Gran Comisión Consultiva del Gobierno en materias relativas a la Reforma Constitucional, y poco después fuimos designados para trabajar en la Sub-Comisión eneargada de preparar el proyecto de Reforma. Esta Sub-Comisión era casi en su totalidad compuesta por hombres públicos, representativos de los diversos partidos, agrupaciones e intereses que han actuado en el país durante los últimos treinta años. Constituía una excepción en tan selecto cenáculo el autor de este libro, hombre de cátedra y nada más, que no representaba allí a nadie, absolutamente a nadie, ni tenía personalidad siquiera aproximada a la de sus distinguidos colegas, aún cuando estaba ligado a la mayor parte de ellos por lazos de vieja amistad con que lo favorecían. Esta situación personal un tanto extraña y aún incómoda, tuvo su compensación en cuanto nos permitió proceder con toda independencia, sin tener en vista otro objetivo que el interés nacional, tal como en conciencia lo entendíamos, y nos permite ahora expresar en las mismas condiciones nuestro juicio, modesto pero desinteresado, respecto de la obra realizada y de la que quedó por realizar.

Nos fué muy grato ver incorporadas al texto de la nueva Constitución casi todas làs reformas que el país reclamaba en vista de las dolorosas experiencias arrojadas por la práctica del régimen parlamentario. $\mathrm{Y}$ desde entonces concebimos el propósito de escribir un libro que fuera el comentario de las reformas realizadas, y la exposición de otras que en aquel momento histórico no se pudieron efectuar, pero que, a nuestro juicio, deberán agregarse en tiempo no lejano. Precisamente, porque consideramos saludable la reforma constitucional verificada en 1925, nos sentimos movidos a desear que se la complete haciendo lo que entonces no se hizo, porque no se pudo o no se quiso hacerlo.

Para ilustrar nuestras opiniones y reforzar nuestros argumentos, invocaremos con alguna frecuencia viejos textos constitucionales de Chile y textos extranjeros viejos y nuevos. Nos valdremos generalmente de nuestras Constituciones de 1828 y de 1833, y en materia de Constituciones extranjeras, sin fatigar al lector con una desparramada erudición, nos limita- 
remos a mencionar talvez una docena y media, justificando su selección por los motivos que vamos a expresar.

Las Constituciones de Inglaterra, de Estados Unidos (17871919) y de Francia (1875) serán invocadas, porque esos tres grandes países han sido, en diversas formas, las cunas del gobierno representativo y los mentores políticos de la Civilización Occidental; las de la República Argentina (1853-1898), Brasil (1891-1924), Cuba (1901-1928), México (1917), Uruguay (1918) y Perú (1919), por ser de países similares al nuestro, por su origen, grado de cultura y necesidades; las del Japón (1889) y Federación Australiana (1901), porque rigen la vida de paises que se encuentran, como el nuestro, en plena evolución progresiva; $y$, finalmente, varias Constituciones nuevas de Europa, porque contienen la solución de problemas contemporáneos que se dejan sentir por igual en pueblos europeos y americanos. A la cabeza de estas últimas va la Constitución Republicana de Alemania (1919) y le siguen las de Finlandia (1919), Cheoeslovaquia y Austria (1920), Polonia (1921-1926), Yngoslavia (1921) y el Estado Libre de Irlanda (1922).

(Las cifras entre paréntesis indican el año de la promulgación de las Constituciones nombradas, y euando hay dos cifras, la segunda indica el año de la última reforma).

Esta obra fué presentada al Certamen Bienal de la Facultad de Ciencias Jurídicas y Sociales de la Universidad de Chile, correspondiente a los años 1926-1927, y fué favorecida con el premio, por acuerdo de la Facultad, de 24 de Diciembre de 1928, adoptado en armonía con el Informe del Jurado, de 18 de Diciembre, suscrito por los señores don Risardo Montaner Bello, don Agustín Vigorena y don Oscar Fenner.

En Infiorme, en lo pertinente a este libro, dice lo siguiente: «La obra de Justus Publicola, titulada: La Reforma Constitucional de 1925 y los efectos del Parlamentarismo en Chile, es la única que realmente tiene todas las condiciones del concurso: ser obra inédita, presentada bajo seudónimo y ser un estudio $y$ comentario completo $y$ armínico de las Reformas Constitucionales de 1925 
«Esta obra tiene méritos como trabajo metódico de exposición, sólida doctrina, vastos conocimientos de la política chilena y abundante comparación de las instituciones chilenas con las instituciones similares extranjeras. Es una crítica circunstanciada de los resultados que produjo en Chile el régimen parlamentario. Contiene ideas bien definidas y fundamentadas, y orientación clara del autor en el sentido de las reformas constitucionales realizadas en nuestro país. De su texto se deduce que su autor es conocedor de todos los móviles de la reforma por haber tomado parte en su realización. Aprecia con entusiasmo la labor realizada, sin dejar por eso de anotar sus deficiencias, para las euales propone los remedios eonducentes a subsanarlas. Su estilo es claro, preciso y sobrio y no exento de colorido.

«Por todas estas someras consideraciones, creemos los miembros del jurado que se debe otorgar el premio de este certamen a la obra de Justus Publicola».

En obsequio a la brevedad, hemos cambiado el título de nuestra obra, llamándola ahora: La Constitución de 1925.

J. G. G. 


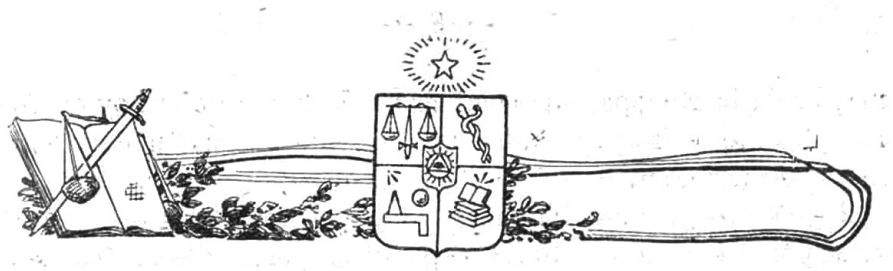

\section{INTRODUCCIÓN}

1.-Las naciones, como los individuos, recorren durante su existencia diversas etapas, que eorresponden a la juventud, la madurez y la decadencia. Suele ser su juventud azarosa y plagada de errores, hijos de la ignorancia y de la inexperiencia, alentados por quiméricas ilusiones; su edad madura se presenta de ordinario reposada y próspera, como recompensa de los sacrificios realizados en la persecución del bienestar; y a la postre suelen producirse verdaderas enfermedades sociales, como la cormupción política y la enervación de las virtudes públicas, que las conducen a la ruina y a la muerte. Esta la más dura e inflexible ley natural a que está sometida la $\mathrm{Hu}$ manidad, según lo demuestra la Historia. Centenares de Estados han nacido, han vivido y han muerto, obedeciendo a lá acción ineludible de factores raciales, monales, religiosos; económicos y políticos, que han obrado fatalmente, empujando hoy a un pueblo en avance triunfal, para precipitarlo después al desquiciamiento y a la nada. Ningún pueblo, por débil y pequeño que sea, está condenado a perpetua nulidad, y ninguno tampoco, sea eual fuere su poderío y su grandeza, puede vanagloriarse de tener clavada para siempie la rueda de la fortuna.

El Nuevo Mundo fué descubierto sólo a fines del siglo $\mathrm{XV}$ por el genio de Cristobal Colón, y, llamado por él a disfnutar la Civilización del Antiguo Continente, es hoy el campo de las más portentosas experimentaciones sociales y políticas, y el que reserva mayores sorpresas para el porvenir. La cultura huinana, đèsplazada del Asia, cuna de las más remotas civilizacio- 
nes, hacia la Europa, que comienza a decaer, retoña hoy en forma pujante e incontrastable, en la vasta extensión del Continente Americano.

2.-De los grandes imperios coloniales formados en la América por los conquistadores españoles, portugueses, franceses e ingleses, surgieron en media centuria, durante el último cuarto del sigla XVIII y el primero del siglo XIX las Repúblicas de Estados Unidos de Norte América, México, Centro América, Haití, Santo Domingo, la Gran Colombia, Perú, Bolivia, Chile, Argentina, Uruguay y Paraguay, y el Imperio del Brasil. Más tarde se fraccionó la Gran Colombia en tres repúblicas: Nueva Granada (Colombia), Venezuela y Ecuador, y se subdividió Centro América en cinco pequeños Eistados: Guatemala, Salvador, Honduras, Nicaragua y Costa Rica. Más tarde aún, en las postrimerías del siglo XIX, se emancipó de España la República de Cuba y se segregó de Colombia la República de Panamá. 'En 1889 el Imperio del Brasil se transformó en República, y desde 1867, el Dominio Británico de Norte América quedó transformado en una República Federal, dependiente de la Corona Británica, que actuó como persona internacional en el Tratado de Versalles de 1918. Existen, por consiguiente hoy veintidós Repúblicas americanas, de las cuales sólo una depende de un Estado europeo.

3.-Son todavía colonias europeas algunas fracciones de menor importancia del Nuevo Mundo. Pertenecen a la Gran Bretaña las colonias de Belice y Guayana Inglesa, en Centro y Sud América, respectivamente; Terranova, las Islas Bermudas y Lucayas, en el Atlántico del Norte; Jamaica, en las Antillas Mayores; Trinidad, en las costas de Venezuela, y las Islas Falkland, en el Atlántico del Sur; de éstas, las Bermudas, Trinidad y la Guayana Inglesa, son colonias representativas, que gozan de autonomía, semejante aunque no igual, a la del Dominio Británico de Norte América. Dinamarca conserva la Groenlandia, y las işlas de Santa Cruz, Santo Tomás y San Juan en las Antillas Menores. Holanda conserva la Guayana Holandesa en la América del Sur, y las islas de Curazao y Bonaire en las costas de Venezuela; finalmente, Francia conserva la Guayana Francesa en Sud-América y las Islas de Martinica, Guadalupe y Marigalante en las Antillas Menores.

4.-Pueden considerarse colonias también, pero no de Estados europeos, sino de la República de los Estados Unidos de 
Norte América, la isla de Puerto Rico, de las Antillas Mayores, medida por España en 1898, y la Zona del Canal de Panamá, cedida en 1902, por la República de Panamá. Estadios Unidos tiene pendientes, además, gestiones de compra de las Islas Danesas de las Antillas Menores.

5.-La suerte de los Estados del Nuevo Mundo, ha sido diversa, guardando relación con su origen y con algunas circunstancias accidentales que conviene señalar, para llegar a una cabal apreciación de sus instituciones políticas y de su situación eultural.

Las primeras colonias que se emanciparon fueron las británicas de Norte América (1774-1777). Fueron ellas trece colonias: cinco correspondientes a la Nueva Inglaterra, y las de l'ensilvania, New York, New Jersey, Maryland, Virginia, las Carolinas y Georgía. Todas ellas tenían territorios más o menos fértiles, que brindaban la subsistencia al trabajo perseverante, pero no tenían riquezas minerales que halagaran al espíritu de enriquecimiento rápido. Fueron colonizadas en la Nueva Inglaterra y en la Pensilvania, por miembros de la religión presbiteriana: puritanos y cuáqueros que, perseguidos en Inglaterra, vinieron a fiundar en el Nuevo Mundo una patria libre y feliz; en Maryland, por católicos perseguidos también durante el reinado de Isabel, y en el resto de las colonias por labriegos que vinieron a cultivar la tierra. A ninguna de ellas vinieron aventureros ávidos de riqueza rápida al precio de cualquier sacrificio. Todos llegaron con sus familias, y trataron de mantener a todo trance la pureza de su sangre, de la raza blanca, sin mezclarse jamás con la raza indígena primero, ni con la raza negra que llegó después a las colonias más meridionales. Desde los primeros momentos, gozarion los colonos de grandes libertades, ya conocidas en Inglaterra y tuvieron la facultad de gobernarse en conformidad a leyes propias de cada colonia. Una de las bases primordiales de su organización. colonial fué la tolerancia para todas las ereencias religiosas y doctrinas políticas.

Las colonias españolas se emanciparon cuarenta años más tarde (1810-1826). Habían sido conquistadas y colomizadas por aventureras que no vinieron al Nuevo Mundo con el pro- 
pósito de radicarse y cultivar la tierra, sino tan sólo de buscar el oro, para enriquecerse rápidamente y volverse a España. Ellos vinieron generalmente sin sus mujeres, y no vacilaron en mezclar su sangre-ya mestizada con los árabes en la península—a la sangre indígena primero y a la negra más tarde, formando una numerosa progenie de mestizos y de mulatos. Conservaron a su lado a los indígenas para explotar su trabajo, so pretexto de acristianarlos, pero sin darles instrucción. Ellos mismos eran ignorantes, y fueron gobernados desde España, sin llegar a adquirir educación política alguna, bajo un régimen de absolutismo y del más ciego exclusivismo católico. Los extranjeros estuvieron rigurosamente excluídos, y la instrucción fué considerada peligrosa. Por otra parte, la mayoría de esas colonias estaban situadas en la zona tropical, cuyo elima enerva la actividad y enardece las pasiones.

Todo lo dicho respecto de las colonias españolas, se puede decir también del Brasil, la gran colonia portuguesa, que ste emancipó en 1823, pacíficamente, adoptando la forma monárquica de gobierno, que sólo reemplazó por la republicana sesenta y seis años más tarde.

6.-Resumiendo las ligeras observaciones anteriores, podemos establecer las diferencias que vamos a expresar, entre-la situación cultural y política de las colonias británicas por un lado, y las españolas y portuguesas por el otro, al momento de emanciparse de sus metrópolis.

Las colonias británicas tenían:

1. La pureza de la raza blanca; $2 .^{\circ}$ Los indígenas arrojados fuera del territorio; $y$ los negros completamente separados, y ésto en las colonias de Virginia, Carolinas y Georgía, únicamente; $3 .^{\circ}$ Clima templado; $4 .^{\circ}$ Territorio escaso en riquezas minerales y apto sólo para la agricultra; $5 .{ }^{2}$ Instrucción mediana; $6 .^{9}$ Bastante edueación política; $7:^{\circ}$ Tolerancia religgiosa.

En cambio, las colonias españolas y portuguesas se encontraban en las condiciones siguientes:

1. ${ }^{\circ}$ Poca población de raza blanca y de mala calidad. Mayoría de población mestizada con indígenas o negros; $2 .^{\circ}$ Grandes masas de población puramente indígena, que en algunas de las colonias llegaba a los nueve décimos del total de habitantes; $3 .^{\circ}$ Clima tropical; $4 .^{\circ}$ Territorios sumamente abundantes en productos minerales, y también en riqueza agrícola; 5. Falta casi absoluta de instrucción; 6. ${ }^{\circ}$ Falta absoluta de 
educación política; 7. Absoluta intolerancia religiosa, y predominio completo del catolicismo.

Chile constituía una excepción, desde ciertos puntos de vista. Le faltó el mestizaje con la raza negra porque la pobreza del país no dió lugar a la importación de muchos esclavos africanos; la convivencia con los indígenas de pura raza, que a virtud de su fiereza, fué preciso relegarlos al sui del río Bio-Bío; el clima tropical, pues el país está comprendido en la zona templada y refrescado por las brisas del mar que lo baña en toda su larga extensión; y las grandes riquezas minerales, que sólo se han venido a explotar después de la emancipación.

7.-Los factores que dejamos enunciados determinaron la suerte que los pueblos americanos han corrido después de su emancipación.

Las colonias británicas, después de un breve período de vicisitudes políticas, pero sin revoluciones, llegaron a darse en 1787 , una Constitución, que es el más perfecto Código Polítieo del Mundo, completamente adecuado a las condiciones del país. Se han desarrolado y crecido en forma portentosa, y só: to han tenido después una gran revolución, la llamada Guerra de Secesión, ocasionada por la agregación, posterior a la Indepeudencia, de los grandes territorios de la Luisiama (1803) y la Florida (1818), en los cuales existían y se desarrollarou grandes masas de esclavos africanos.

El Brasil, a la sombra de una monarquía temperada, armónica con su estado cultural, pudo desarrollarse, con pocas revoluciones, hasta que una evolución lenta, pero segura, le permitió abolir la esclavitud y adoptar la forma republicana, conservando la unidad nacional (1889).

I Chile, después de un corto periodo de agitaciones (18181831) Hegó a darse una Constitución, la de 1833, que correspondía ampliamente a su estado cultural, y que le permitió vivir y desarrollarse, durante noventa años, sin tener duraute ese largo período más que tress revoluciones sangrientas, (n) 1851, 1859 y 1891, y dos revoluciones ultra pacíticas (1924 y 1925), hasta llegar a la Reforma Constitueional de 1925, que nos proponemos estudiar en sus eausas, en su alcance actual $y$ en sus expectativas para el porvenir.

Los demás países americanos, desde México hasta la República Argentina, han pasado gran parte de su vida independiente agitados por sangrientas revoluciones, fluctuando en- 
tre despotismos horrorosos y utopías libérrimas, hasta llegar al estado de equilibrio inestable en que hoy se encuentra la mayor parte de ellos. En todos estos países, ha prevalecido la forma republicana de gobierno, y las revoluciones hạ provenido, generalmenite, de las carsas siguientes: $10^{\circ}$ el predominio del elemento militar; $2 .^{\circ}$ la inmoralidad de los políticos; $3 .^{\circ}$ el espíritu regionalista; $4 .^{\circ}$ la fluctuación entre el régimen federal y el unitario; $5 .^{\circ}$ la disidencia entre los católicos y los librepensadores; $6 .^{\circ}$ la coexistencia de clases aristocráticas absorbentes y masas populares ignorantes; y $7 .^{9}$ la existencia de grandes masas de población indígena.

En tres repúblicas americanas se ha presentado un verdadero fénómeno de recolonización europea, por medio de fuertes corrientes de inmigración. Son ellas, los Estados Unidos, la República Argentina y el Brasil. Los efectos han sido diversos. En los Estados Unidos han penetrado millones de individuos de todas las nacionalidades europeas, desde las más adelantadas hasta las que se encuentran en decadencia, y se ha llegado a producir el convencimiento de que la inmigraeión procedente de los países del norte de Europa, es favorable al desarrollo y bienestar nacional, mientras que la inmigración de individuos del sur y del oriente de Europa es desventajosa. También se ha estimado perjudicial la inmigración de individuos de la raza amarilla, procedentes del Asia. Entre tanto, en la República Argentina y en el Brasil, las corrientes inmigratorias, procedentes en su mayor parte del sux de Élropa, han contribuído enormemente al desarrollo económico y cultural de las dos naciones.

En el resto de las repúblicas hispano-americanas, las corrientes inmigratorias han ejercido una influencia mucho menor, aunque siempre apreciable, por no haber asumido grandes proporciones.

Una buena parte del caudal inmigratorio es de procedencia española en las repúblicas hispanas y portuguesa en el Brasil. En ambos easos ha producido buenos resultados, por ser estos inmigrantes posteriores a la emancipación, gentes de trabajo, muy superiores a los simples aventureros del período de la Conquista y de la Colonia. 
8.- La evolución constitucional de Chile, considerada en sus rasgos más sobresalientes, se puede dividir en cuatro períodos: 1.9. el comprendida entre el 18 de Septiembre de 1810, fech: de la reunión de la primera Junta de Gobierno Nacional, y el 4 de Octubre de 1814, fecha del desastre de Rancagua, que comprende el período histórico de la Patria Vieja; $2 .^{\circ}$ el comprendido entre el 5 de Abril de 1818, fecha de la batalla de Maipú, que aseguró definitivamente la Independencia Nacional, y el 25 de Mayo de 1833, fecha de la promulgación-de la Constitución que por más largo tiempo ha regulado la vida de la República; $3 .^{\circ}$ el comprendido desde la vigencia de la Constitución de 1833 hasta el triunfo de la sangrienta rev" lución de 1891 ; y $4 .^{9}$ el transcurrido desde Agosto de 1891 has. ta e: 18 de Septiembre de 1925, fecha t? la iromulgación de la Reforma Constitucional efectuada ese año.

Procuraremos sintetizar tan fiel y brevemente como nos sea posible, las características de cada uno de estos períodos.

9.--El primer período, con sólo tres años de duración, en medio de las angustias de la guerra, y faltando en el país la experiencia y la ilustración política necesaria, fué fecundo en documentos constitucionales y estéril en resultados. Fueron. promulgados en tan breve tiempo: $1 .^{9}$ el Reglamento para el arreglo de la Autoridad Ejecutiva Provisoria de Chile, sancionado el 14 de Agosto de 1811; $2 .^{9}$ el Reglamento Constitucional Provisorio, sancionado y jurado el 27 de Octubre de 1812; y $3 .^{\circ}$ el Reglamento para el Gobierno Provisorio, sancionado el 17 de Marzo de 1814. Todos estos Reglamentos no pasan de ser simples ensayos de organización política transitoria, inspirados en el propósito de salvar las dificultades del momento.

10.-El segundo período, de 15 años de duración, comienza en el momento en que la Independencia Nacional quedó definitivamente asegurada con el triunfo de Maipú. Se pensó entonces, no en una organización provisional del Gobierno, sino en la necesidad de asentar sobre bases sólidas y estables la organización política deł Estado. Se promulgaron en ese tiempo einco documentos que son verdaderas Constituciones: $1 .{ }^{9}$ la Constitución Provisoria para el Estado de Chile, sancionada y jurada el 23 de Octubre de $1818 ;, 2 .^{\circ}$ la Constitución Políti- 
ca del Estado de Chile, sancionada y promulgada el 30 de Octubre de 1822 ; $3 .^{\circ}$ el Reglamento Orgánico y Acta de Unión del Pueblo de Chile, acordado por los Plenipotenciarios de la República el 30 de Marzo de $1823 ; 4^{\circ}$ la Constitución Política de la República de Chile, promulgada el 29 de Diciembre de 1823, y 5.9 la Constitución Política de la República de Chile, promulgada el 8 de Agosto de 1828 .

Durante este periodo se nota un considerable aumento de la ilustración política en la clase dirigente del país, adquirido en la lectura de libros y documentos constitueionales de procedencia francesa, norteamericana y española; pero persiste, atinqte atenuada, la inexperiencia política de los directores de la opinión pública naciente, que los induce a confiar demasiado en la eficacia intrínseca de los buenos preceptos constitucionales de otros países, prescindiendo de su adaptabilidad a las condiciones peculiares de Chile. Se caracterizan las Constituciones de ese tiempo por la imitación, y aún la ciega reproducción de los preceptos políticos adoptados por pue. blos muchō más civilizados que el nuestro, y de estructura y antecedentes completamente diversos.

Ejereía amplia influencia el elemento militar triunfante en las recientes campañas de la Independencia de Chile y del $\mathrm{Pe}$ rú, que se consideraba llamado al mando de la flamante República; se agitaba espasmódicamente el pueblo, llamado a la libertad en forma repentina, con un pasado histórico de sumisión absoluta durante el período colonial y el de la reconquista, y perturbaba el buen sentido del público cierta corriente féderalista que no correspondía en manera alguna a la naturaleza unitaria del país.

Las dificultades de la situación se agrandaban por la acritud de las pasiones que dividían a las fracciones o'higginista y carrerina, y à los partidos pelucón y pipiolo, que en cierta manera se podrían clasificar como conservador y progresista respectivamente $\mathrm{y}$ que se enrostraban recíprocamente una larga cadena de resentimientos magnificados por la estrechez del ambiente.

La evolución constitucional de Chile pudo y debió detenerse, con gran provecho para el país, con lá promılgación de la Constitución de 1828, la cual, salvo detalles susceptibles de ser mejorados por medio de reformas parciales, se aproximaba a las condiciones y necesidades de Chile en aquella época. Pero 
el ardor de las pasionés políticas en juego no dió lugar al ejer cicio tranquilo de aquella Constitución; estalló una revoluciórs qute terminó oon la sangrrienta batalla de Lireay (17 de Abril de 1830) y llevó al poder al partido conservador, anheloso de dar al país una nueva Constitución.

11.-El tercer período de la evolución constitucional de Chile, comienza el 25 de Mayo de 1833, con la promulgación de la Constitución preparada por el partido conservador, cuyo caudillo e inspirador era el gran polítieo don Diego Portales Vi. ce-Presidente de la República y. Ministro omnipotente de la presidencia del General don Joaquín Prieto (1831-1841). Aunque el texto mismo de la Constitución sea una obra «impersonal», como lo expresa muy bien el jurisconsulto don Alcibíades Roldán, no cabe dudar que sus tendencias directivas fueron inspiradas por el espíritu práctico y sensato, a la vez que patriótico y enérgico del Ministro Portales, quién, sin tener una vasta ilustración en materias de doctrina constitucional, era en cambio un acabado exponente del buen sentido y un experto conocedor de la sicología y de la cultura del pueblo chileno de aquella época (1).

- Dos fueron los fines fundamentales que persiguieron los autores de la Constitución de 1833: un fin partidarista, el de asegurar por largo tiempo el mantenimiento de su partido en el poder, y un fin patriótico, el de poner término a las revolu=

(1) Las ideas políticas y constitucionales de Portales están muy bien expresadas en una carta escrita por él cuando tenía 28 años de edad, lesde Lima y con fecha 22 de Marzo de 1822, a su socio don José M. Cea, residente en Valparaíso. De ella copiamos el párrafo siguiente, tomándolo de la pág. 63 del libro titulado: Valparaíso en 1827, por don Roberto Hernández:

«La Democracia que tanto pregonan los ilusos, es un absurdo en los países como los americanos, llenos de vicios y donde los ciudadanos carecen de toda virtud como es necesario para establecer una verdadera República. La Monarquía no es tampoco el ideal americano: salimos de una terrible para volver a otra by qué ganamos? La República es el siste. tha que hay que adoptar: pero $b$ sabe como yo la entiendo para estos países? Un gobierno fuerte, centralizador, cuyos hombres sean verdaderos modelos de virtud y patriotismo, y así enderezar a los ciudadanos por el camino del orden y de las virtudes. Cuando se hallen moralizados, venga el gobierno completamente liberal, libre y lleno de ideales donde tengan parte todos los ciudadanos. Esto es lo que yo pienso y todo hombre do mediano criterio pensará igual». 
ciones asentando sobre sólidas bases el funcionamiento de los Poderes Públicos.

Para realizar sus objetivos, comenzaron por apartar el espíritu de ciega imitación de las instituciones extranjeras, por grandes que fueran los benefieios por ellas producidos en los respectivos países, adivinando que las instituciones no tienen una eficacia cabalística, sino el valor que les dá su adecuación a las condiciones del ambiente humano y físico en que han de ser aplicadas. Imitaron y hasta copiaron literalmente, pero realisando antes una crítica razonada y prudente. Esto los llevó a generar una Constitución escencialmente nacional, más aún, criolla, que lleva el sello del trabajo hecho por chilenos, en Chile y para Chile, diferenciándola notablemente de algunos de los trabajos análogos realizados en el período anterior entre nosotros, y de algunas Constituciones construídas en otros países americanos a base de la copia servil de instituciones extranjeras.

En seguida, comprendieron una gran verdad, que es a menudo desconocida en todas partes del mundo, la de que la libertad no es el objetivo, el fin de la existencia tanto individual como eolectiva, sino un medio para realizar el verdadero fin de nuestra especie, que es la conservación y el desarrollo de la vida misma, sea ella la de un hombre o la de una $\mathrm{Na}$ eión. Deducción lógica de esta tesis, es que la libertad puede producir tanto bienes como males, según se armonice o se contraponga con los otros medios de acción social, como la riqueza, la inteligencia, la eultura, la moral, etc. Así, no será la mejor Constitución la más liberal ni la menos liberal, sino la que consulte un régimen proporcionado a las aptitudes de un pueblo en un momento dado de su evolución, de tal manera que la preciosa Constitución de los Estados Unidos resultaría un desatino en la Persia, y la organización del Imperio Persa no se podría aplicar en los Estados Unidos. Esto parece obvio hoy día-y no a todos- pero en 1833 sólo se comenzaba a columbrar esta verdad.

Finalmente, comprendieron los constituyentes de 1833, que el mayor interés de una colectividad es que exista un Gobierno, bueno o malo, pero estable y eficiente. El ideal en esta materia varía hasta lo infinito, a la medida de la cultura y de los intereses de cada individuo, pero siempre resulta que el más tiránico e inmoral de los Gobiernos estables y fuertes, será 
preferible a la anarquía absoluta, o a la anarquía relativa que significa la inestabilidad o la debilidad de la autoridad pública.

En armonía con los principios fundamentales expuestos, los constituyentes de 1833 organizaron un mecanismo político, de apariencia republicana y de fondo monárquico, a base de un predominio incontrastable del Presidente de la República, jefe del Poder Ejecutivo, sobre el Poder Legislativo y sobre el Poder Judicial. Con intención deliberada, crearon en realidad un tipo específico de Constitución netamente presidencial, en la cual el «Jefe Supremo de la Nación» estaba revestido de la mayor suma de poder que se puede encebir en una democracia, dando así amplia satisfaicción a la más primordial necesidad de los pueblos jóveness, que es la eficiencia de la autoridad directiva.

A la sombra de la Constitución de 1833, entró Chile por ?a vía del orden público prudentemente armonizado con la libertad individual. Se estabilizaron las finanzas públicas, se desarrolló la riqueza privada, se estimuló la entrada de los extranjeros, se fundó un sistema de instrucción pública en todos los grados, se eomenzó a formar la clase media desconocida en el tiempo colonial, y se abrió el camino para reformas mesuradas y oportunas.

El período de la vigencia de la Constitución de 1833, aunque aparentemente se extienda hasta el año 1925, terminó en realidad en Agosto de 1891, con el triunfo de la Revolución iniciada ese año por la mayoría del Congreso Nacional. Duró por eonsiguiente cincuenta y ocho años, que se pueden distribuir en dos partes o subdivisiones:

a) Durante los años comprendidos entre 1833 y 1871, la Constitución rigió en su forma primitiva, sin modificación alguna de su texto, y sin más alteraciones que las que importaron tres leyes interpretativas, dos de las cuales fueron de poco alcance, y sólo una revistió importancia capital, la de 1865 , que bajo la forma de una simple interpretación del art. $50^{\circ}$ de la Constitución, importó en el hecho, una substancial reforma, por cuanto estableció de facto, la libertad de cultos, que la Constitución no reconocía. En el transcurso de esas cuatro décadas, se desarrolló en el país el anhelo de reformas liberales, evolucionaron los antiguros partidos políticos y nacieron otros nuevos. Llegaron a producirse dos sangrientas revoluciones, la de 1851 y Ta de 1859 , y se diseñaron tres aspiraciones funda- 
mentales: ampliar las libertades individuales, aumentar las influencias del Congreso y restringir las facultades del Presidente de la República.

b) El año 1871, meses antes de la elección del Presidente liberal don Federico Errázuriz Zañartu, comienza una segunda etapa de la vigencia de la Constitución de 1833, en la cual llegaron a realizarse en gran parte los anhelos de reforma tan ardorosamente sostemidos en las décadas anteriores; ello se efectuó por medio de siete leyes de reforma aprobadas desde el año 1871 hasta el de 1888, siendo las más importantes las realizadas en 1874. Todas esas reformas se realizaron en la forma prescrita por la Constitución misma; pero aún cuando importaron modificaciones substanciales en los puntos que tocaron, dejaron en pie el carácter esencialmente presidencial de la Constitución.

El Presidente de la República continuó siendo en realidad el «Jefe Supremo de la Nación» tal como lo expresaba el texto constitucional y como lo habían querido sus autores en 1833. Este era precisamente el blanco de los mayores ataques contra la Constitución vigente. Los caudililos políticos con asiento en el Congreso, no se resignaban al papel meramente legislativo y fiscalizador que les atribuía la Constitución, en presencia del poder efectivo y amplio de Gobierno que correspondía al Presidente de la República; deseaban reducir en cuanto fuera posible la omnipotencia presidencial y aumentar en análoga proporción la influencia de los miembros del Congreso.

Esta tendencia se venía manifestando desde la Presidencia de don Manuel Montt (1851-1861); pero, como los Congresos eran elegidos bajo la presión interventora de los Gobiernos, no se llegaron a producir conflictos de gravedad entre el Poder Ejecutivo y el Poder Legislativo, sino en contadas ocasiones, en que el buen sentido y el patriotismo de los políticos permitió terminarlos por medio de procedimientos conciliatorios. En el fondo de esta competencia, germinaba la lucha entre dos sistemas de gobierno, el presidencial establecido por la Constitución vigente en Chile, y el parlamentario que importa el predominio del Congreso sobre los otros dos poderes públicos, y que, creado en Inglaterra donde produjo buenos resultados durante un siglo, fué también implantado en Francia al establecerse por tercera vez la forma republicana de Gobierno en 1871, como lo había sido también por varias monar- 
quías constitucionales de Europa, y por el Imperio Constitucional del Brasil.

Varios factores contribuyeron al desarrollo de las ideas parlamentaristas en Chile, en los cuarenta años transcurridos desde 1851 hasta 1891. Trataremos de compendiar los principales.

En primer lugar, el sistema entronizado de generar los Congresos por medio de la intervención gubernativa se fué hacien. do cada vez más irritante, a medida que el desarrollo de la cultura infundió en mayor número de espíritus cultivados el deseo de ver respetados los derechos cívicos. En segundo término, los abusos del Gobierno, inevitables en todo pueblo de escasa eultura moral, se atribuyeron al régimen de omnipotencia presidencial, porque era presidencial el Gobierno que los cometía.

Estos dos grandes factores fneron aprovechados por los caudillos de opasición, que, no teniendo participación directa en el Gobierno, querían ejercerla indirectamente desde sus bancos en el Congreso, y por eso reclamaban el aumento de sus facultades, so capa de combatir la omnipotencia presidencial. Algunos hombres de Gobierno contribuyeron al mismo propósito, manifestándose respetuosos de votos parlamentarios adversos, por convicción en unos casos y por simple espíritu de conciliación en otros.

Ejerció también gran influencia el espíritu de imitación apasionada e irreflexiva. Los políticos de tendencia conservadora invocaban el ejemplo de Inglaterra, bien gobernada, según ellos, a consecuencia de la práctica del sistema parlamentario, y los políticos liberales o radicales se inclinaban al parlamentarismo por adhesión a la Francia que lo había adoptado, sin parar mientes en que ese sistema produjo en aquel país malos resultados desde el momento mismo de su implantación.

Los que invocaban el ejemplo de Inglaterra, se echaban a la espalda las condiciones de buen sentido, de cultura moral y de educación política de aquel país, muy superiores, por cierto, a las del nuestro; olvidaban también que el parlamentarismo británico se había generado naturalmente, como consecuencia de la contraposición de la autoridad absoluta de sus monarcas con la soberanía creciente del pueblo representado por la Cámara de los Comunes, fenómeno que no existía en Chile, y por último, prescindían del hecho de que en Ingla- 
terra misma ya se comenzaba a experimentar los defectos de] sistema, como lo expresó uno de los más eminentes filósiofos del siglo XIX, Herbert Spencer, euando dijo que después de haber destruído la omnipotencia de los Reyes, el pueblo británico tenía delante de sí el problema de destruir la omnipotencia del Parlamento.

En las Constituciones nuevas de Europa, dictadas despuês de la Guerra Mundial tanto en Alemania como en los Estados creados por el Tratado de Versalles, se ha establecido generalmente el sistema parlamentario, perseverando en la imitación de Inglaterra. Pero ya en Alemania muchos y muy buenos patriotas esitán clamando por la supresión del parlamentarismo. $\mathrm{Y}$ en Polonia, a los cinco años de vigencia de su Constitución Parlamentaria, se produjo una revolución que la reformó el 2 de Agosto de 1926, con el fin de subsanar los abusos del Parlamento. En esa reforma se estableció la vigencia automática del Presupuesto del Gobierno para tos casos en que la Dieta y el Senado no los aprobaren oportunamente; la facultad del Presidente de la República de disolver la Diata una vez durante su período de mando; la facultad presidencial de dictar Ordenanzas-Leyes (equivalentes a nuestros Decretos-Leyes) en el tiempo intermedio entre la disolución de una Dieta y la instalación de otra nueva, con la obligación de someterlas a la aprobación de ésta última; y, lo que es más significativo aún, varias disposiciones tendientes a evitar los logros indebidos e inmorales de los parlamentarios.

Los parlamentarios han abusado aún en países que no tienen establecido el sistema parlamentario. En Estados Unidos se ejercita escandalosamente la obstrucción, y en el Brasil se abusó tanto que fué preciso reformar la Constitución en 1924, estableciendo, entre otras cosas, la prórroga automática del presupuesto anterior, $\mathrm{y}$ de la ley anual de fuerzas de mar y tierra, cuando una u otra de estas leyes no hubieren sido despachadas por el Congreso para entrar en vigencia antes del 15 de Enero de cada año.

A nuestro juicio, el sistema presidencial establecido por la Constitución de 1833, respondió ampliamente a las condiciones y necesidades del país en la época y circunstancias en que fué iniciado; pero, cimentado el orden público, y desarrollada, aunque en pequeña escala, la eultura nacional, se hacía necesario reformarlo, en el sentido de aproximar nuestro meca- 
nismo político al que se dió un siglo antes la República de los Estados Unidos, propendiendo en primer lugar al establecimiento de la libertad electoral, y continuando la evolución reformista comenzada en 1871, hasta llegar a un prudente equilibrio de los Poderes Públicos.

Decimos esto, autorizados-no por las luces del talento ni de vasta ilustración-pero sí por la experiencia de una vida que ya ha pasado los linderos de la madurez, por la imparcialidarl que nos permite una sistemática y meditada abstención de las luchas políticas, y finalmente, por el conocimiento de los hombres $y$ de los acontecimientos de nuestro país durante los ́iltimos cuarenta años. Nuestras convicciones no han sido extraídas de los libros ni originadas por intereses; son únicamente el fruto de la observación serena y persistente de la evolución que a nuestra vista se ha desarrollado en la tierra natal.

12.-El triunfo de la revolución de 1891, inicia el cuarto período de nuestra evolución constitncional. Generada aquella revolución por simples dificultades electorales, a consecuencia de una candidatura presidencial patrocinada por el Presidente Balmaceda y fuertemente resistida por la mayoría de los partidos políticos, encontró eco en la opinión pública independiente, fatigada por el sistema de la intervención gubernativa en todas las eleceiones y estimulada por los caudillos políticos contra la omnipotencia presidencial.

Los revolucionarios triunfantes desquiciaron por completo el régimen político establecido por la Constitución de 1833 , sin efectuar reformas de gran bulto en el texto mismo de ese documento. Procediendo de hecho, comenzaron el aniquilamiento de la antoridad presidencial, y en el transcurso de pocos años llegaron también a supeditar la autoridad de los Ministros de. Estado, haciendo pasar una y otra; en forma progresiva $y$ sistemática, a los miembros del Congreso. Traicionaron de este modo ell texto y el espíritu de la Constitución, pues reemplazaron la autoridad unipersonal y responsable del Presidente de la República por la dictadura colectiva, irresponsable e intangible de los ciento veintiocho eiudadanos que formaban las dos ramas del Congreso, y que más tarde llegaron a ser ciento eincuenta y cinco.

A grandes zancadas, todo el mecanismo de la administración pública fué pasando del Poder Ejecutivo, a manos del 
Congreso, gracias a la implantación inconstitucional del régimen parlamentario, mediante el uso abusivo que las Cámaras hicieron de la facultad de aprobar periódicamente las leyes de presupuestos y de contribuciones, de la que regulaba el mantenimiento de la fuerza armada, de la que permitía la permanencia de fuerzas militares en la ciudad residencia del Congreso, y de toda otra ley que tuviera una importancia vital para la marcha del Estado. A la acción tiránica y absorbente de las mayorías de las Cámaras, se añadió la acción perturbadora de las minorías y aún de ambiciosos aislados, que, gracias a la imperfección de los Reglamentos internos de estas corporaciones, hacían prevalecer sus intereses por medio de la obstrueción.

Diputados y senadores, ansiosos de poder y de lucro àlgunos, y movidos otros por el deseo de asegurar sus reelecciones, fueron cada día más preocupándose de acrecentar sus influencias personales 0 partidaristas en el manejo de los negocios públicos, sin tomar en euenta los intereses de la Nación. A título de fiscalizar los aetos del Gobierno, formaban las más extrañas e híbridas combinaciones numéricas para derribar los Ministerios, y descuidaron la labor legislativa en términos tales que colocaron al país en una situación de retraso considerable con relación a los demás de Sud-América. El escaso progreso realizado por Chile durante los treinta y cinco años que ha durado el régimen parlamentario, se ha conseguido gracias al inaudito esfuerzo de los habitantes del país y a la vitalidad exhuberante propia de los pueblos jóvenes, a pesar del Congreso y contra el Congreso.

Todo este conjunto de desaciertos y de malas prácticas políticas se ha verificado violando las disposiciones expresas y el espíritu reconocido de la Constitución de 1833, que en la apariencia se mantenía vigente y que en la realidad había sido abrogada. Por eso, consideramos nosotros que, a partir de 1891, régimen constitucional quedó suspendido, y el país ha languidecido bajo la dictadura del Congreso en pleno régimen de inconstitucionalidad.

Espíritus honrados, pero un tanto teóricos, han creído que los males de Chile provenían de una aplicación exagerada y abusiva del régimen parlamentario, de algo que podría considerarse como un parlamentarismo criollo, pero que no eran inherentes al sistema mismo. Nosotros hemos disentido siempre 
de esta opinión; siempre hemos pensado que no hay parlamentarismo bueno y parlamentarismo malo, sino que, siendo el régimen parlamentario un artificio completamente inconexo con las necesidades naturales del Gobierno, es intrínsecamente malo, pues lleva en sí mismo el germen de todos los extravíos, que se desarrollan fatalmente a la larga o a la corta, a la medida de la mayor o la menor. cultura moral de la Nación en que se aplica, de la misma manera que una enfermedad será siempre enfermedad y sus estragos aparentes serán mayores o menores en proporción al temperamento y robustez de cada individuo.

A la observación de nuestra propia patria podemos añadir la experiencia de otros países. Con motivo del derrumbe de la monarquía absoluta de origen divino, que ha caracterizado la evolución política de la Europa en el siglo XIX, se organizaron en aquel Continente varias monarquías constitucionales, de régimen parlamentario, a base de la imitación del sistema existente en Inglaterra. La Europa Continental imitó a la Inglaterra, en forma semejante a la América Latina que imitó a los Estados Unidos. Pero a breve plazo, que no ha alcanzado a completar un siglo, se ha podido comprobar el fracaso del régimen parlamentario, pues aparte de un mediano funcionamiento en Inglaterra, Holanda, Bélgica, Suecia, países de una elevada cultura moral, el parlamentarismo se ha mostrado ineficaz en los demás países, $\mathrm{y}$ ha llegado a los últimos extremos de la depravación en Francia, Italia y España, países de cultura moral inferior, análoga a la nuestra.

En Chile, a partir de 1891, fué creciendo día a día el predominio del Congreso, endiosado por el triunfo de la revolución de aquel año nefasto. Antes de veinte años el nuevo régimen habia dado ya todos sus frutos y la opinión independiente,-aquella que no obedece ciegamente a las consignas de los partidos políticos, - se daba cuenta de que la destrucción de la potestad presidencial lejos de ser un bien, llevaba al país a su más completa ruina. Esa opinión se tornó en contra de la omnipotencia del Congreso, y cuando fué elegido Presidente de la República el señor don Pedro Montt, muchos de sus electores manifestaban la esperanza de que aquel político refrenara las intemperancias parlamentarias y llegara, en último término, a la clausura del Congreso.

Fallidas aquellas esperanzas, el desgobierno parlamentario continuó despeñando al país en una serie de descalabros finan- 
cieros, internacionales, morales y administrativos con la vertiginosa rapidez de la progresión geométrica. Cada nuevo Congreso parecía complacerse en traspasar los límites alcanzados por los anteriores en la via crucis descendente por donde se empujaba a la Nación. La frase lapidaria de Mae-Iver: « Cómo baja la Cámara, cómo desciende el país !» no fué una simple metáfora del gran orador sino la doliente expresión de una desgraciada realidad.

Al comenzar el año 1924, la descomposición política del país alcanzaba sus últimos extremos y hasta los espíritus menos previsores comprendían que la gravedad de la situación entrañaba la posibilidad de una gran perturbación del orden público. Los dirigentes políticos se sintieron amedrentados y temieron que el Presidente Alessandri, alentado por la opinión pública, los eliminara del Congreso que se debía elegir a principios de Marzo. El instinto de la propia conservación los movió entonces a aceptar algunas modificaciones en el régimen político-constitucional que, sin lastimar sus intereses particulares, ejercieran una influencia sedante en el ánimo del pueblo. Se produjo entonces un acuerdo entre el Presidente y los caudillos políticos, para aprobar las leyes N.os 4001, 4002, 4003, 4004 y 4005 , promulgadas el 26 de Febrero y publicadas en el Diario Oficial del mismo día. Todas esas leyes, de precipitada gestación, deficiente eficacia y dudosa constitucionalidad, llegaron tarde, a nadie engañaron y fueron impotentes para atajar el derrumbe definitivo del régimen parlamentario.

13.-Los infortunios políticos de Chile llegaron a hacer crisis por un incidente de secundaria importancia, como sucede en todas las cosas de la vida, en que una chispa produce un incendio y una gota de agua el desborde de un vaso ya colmado. El Congreso elegido en Marzo de 1924, perseverando en el camino que le trazaban los anteriores, se ocupó únicamente en diseusiones más o menos bizantinas, desentendiéndose por completo de los intereses nacionales. Llegó a diseutir y aprobar un proyecto de ley que establecía la dieta parlamentaria en violación abierta y descarada de la Constitución. Para nosotros, que consideramos abrogada la Constitución misma desde el año 1891, aquel incidente no es sino un eslabón más en la eadena de trasgresiones que ceñía el cuello de la República; pero, a los ojos de la gran mayoría de nuestros concindadanos, que consideraban vigente la Constitución, aquel acto asumió 
las proporciones de un inaudito atentado que conmovió profundamente los espíritus, de un extremo al otro del país, y en todas sus capas sociales.

La revolución estalló en todos los corazones de los chilenos que no eran partes interesadas en el atentado. No fué la magnitud del hecho mismo lo que enardeció el espíritu público, - pues cosas peores había soportado duranite más de treinta años la idiosinerasia indolente y pacata de nuestra raza. Hubo una serie de pequeños incidentes que se acumularon alrededor del acontecimiento y que acentuaron en él la significación de síntoma extremo de una enfermedad largamente sentida $y$ euya crisis se deseaba ardientemente.

El sentimiento nacional encontró sus fieles intérpretes en las fuerzas armadas de la República, que ofrecieron a la América un espectáculo que nunca se había presenciado en el Continente. La oficialidad de la guarnición de Santiago, dejándose arrastrar por el impulso de una corazonada patriótica, invitó a la de la marina, y casi sin deliberación, se aunaron ambas para llevar al Gobierno, no a un caudillo político, ni tampoco a un caudillo militar, sino simplemente a sus superiores jerárquicos en la administración militar. No tuvieron el prósósito de deponer al Presidente de la República, ni de clausurar: el Congreso, sino tan sólo el de imponer el Veto de la ley de la dieta parlamentaria y la dictación inmediata de una serie de leyes reclamadas por las necesidades del país y preteridas en los archivos de las Cámaras, objetivos que consiguieron sin difieultad.

La opinión pública independiente de los partidos,-que forma la gran mayoría de los habitantes de la República,- - acogió con entusiasmo el levantamiento militar del 5 de Septiembre de 1924, convencida de que él respondía al verdadero interés nacional y no a los intereses particulares de una u otra de las fracciones políticas que se disputaban el predominio en el manejo del Estado. Este fué el secreto del triunfo del movimiento militar, en un país que no es militarista y en el cual la influencia militar estaba anulada desde el advenimiento de don Diego Portales al poder en 1831.

El Presidente de la República don Arturo Alessandri Palma resolvió abandonar su cargo y ausentarse del país. Asumió el mando una Junta Militar que procedió a disolver el Con. greso. Los promotoress de la Revolución dieron entonces al país 
un Manifiesto, el 11 de Septiembre, en el cual expresaron categóricamente su propósito de servir tan sólo los intereses nacionales, prescindiendo de toda influencia de los partidos políticos.

La opinión pública y los militares aspiraban de consuno a la modificación radical de la organización política de la República en términos de que, fuere cual fuere la corriente que llegara a dominar en el país, ella se encontrara con instituciones que le permitieran realizar un Gobierno efectivo y eficaz. Para alcanzar este fin era preciso organizar de nuevo los registros electorales, que se encontraban viciados, realizar elecciones que tradujeran la expresión verdadera de la voluntad nacional y proceder a la reforma constitucional en condiciones de robustecer la autoridad del Ejecutivo y limitar prudentemente dentro de su esfera propia las facultades del Poder Legislativo.

Pero los partidos políticos no quisieron darse cuenta del alcance de la revolución del 5 de Septiembre, ni tomar en serio las declaraciones patrióticas contenidas en el Manifiesto militar del 11 de Septiembre. Los caudillos de las fracciones en lucha pusieron en juego todas sus argucias para inclinar la balanza del lado de sus intereses contrapuestos. Los que más se eegaron fueron talvez los que habían sido adversarios del Presidente Alessandri; éstos no quisieron ver que la revolución no había sido hecha contra aquel mandatario, sino contra un sistema de desgobierno caracterizado por el predominio irresponsable del Congreso. Se llegó a decir que el levantamiento del 5 de Septiembre de 1924 era la reproducción del levantamiento del 7 de Enero de 1891, lo que importaba el profundo error de invertir por completo su significación. La revolución de 1891 abrió el camino al régimen parlamentario en Chile, mientras que la de 1924 tenía por objeto principal poner término a ese régimen.

Los avances reaccionarios se fueron acentuando, hasta que su propia audacia ocasionó su fracaso. Dos acontecimientos alarmaron principalmente a la opinión pública, progresista en su inmensa mayoría, y a los revolucionarios militares que eran sus intérpretes. Los elementos reaccionarios embarcaron al señor Arzobispo de Santiago en la aventura de presentarse personalmente a la Junta de Gobierno en solicitud del establecimiento del sistema de Universidades libres, que suscita las 
más ardientes resistencias entre los espíritus progresistas de Chile, petición que felizmente no fué acogida. Poco después, reunidos en una gran Convención, proclamaron candidato a la Presidencia a un caudillo joven, singularmente caracterizado por sus arrestos oligárquicos.

Los revolucionarios del 5 de Septiembre de 1924 vieron seriamente amenazada la obra que habían emprendido y, considerando que la Junta de Gobierno se había desviado del objetivo inicial, la sustituyeron por otra nueva Junta el 23 de Enero de 1925, para que gobernara al país hasta el regreso del Presidente Alessandri, a quien se llamó inmediatamente.

El Presidente Alessandri aceptó ocupar de nuevo la Presidencia, a condición expresa y terminante de convocar una Asamblea Constituyente, con el objeto de reformar en puntos substanciales la Constitución de la República. Pero, una vez regresado al país, se vió en el caso de luchar contra las dos corrientes opuestas de los partidos políticos, para llegar a realizar las aspiraciones del país, que eran las suyas propias y las de los revolucionarios militares de Septiembre y de Enero. Los políticos de la Alianza Liberal solicitaban desesperadamente la reapertura del Congreso disuelto por la primera Junta de Gobierno, mientras los de la Unión Nacional reclamaban la pronta convocatoria a elecciones de un Congreso ordinario; una y otra corriente eran adversas a la idea de una reforma constitucional seria y substancial que importara la supresión del régimen parlamentario, del eual habían usufructuado unos y otros, con perjuicio para el país que anhelaba precisamente esa reforma, como aspiración suprema sine qua non. Los partidos políticos, en esta materia, se limitaban a promesas vagas y procedimientos paliativos encaminados a desviar a la opinión nacional, hacia la adopción de reformas de poca monta que nada habrían remediado.

14. -El Presidente Alessandri supo sobreponerse a las pretensiones de los partidos, para servir a las legítimas aspiraciones del pueblo chileno, y enderezó abiertamente el rumbo hacia la reforma constitueional. Convocó a un cierto número de políticos militantes escogiéndolos entre los personajes más selectos de todos los partidos, a los que agregó un buen número de 
personas alejadas de las luchas políticas, tomándolas de las diferentes ramas de la actividad nacional. A esta Asamblea cívica, de carácter meramente consultivo, comunicó sus planes de reforma, invitándola a prestarle su cooperación en el estudio de la materia; y de la reunión resultó la designación de dos Sub-Comisiones, señaláda la una para efectuar el análisis de la Constitución y la preparación del proyecto de reforma, y la otra para estudiar el procedimiento con que el proyecto debería ser aprobado.

Las dos Sub-Comisiones designadas tomaron rumbos. y tavieron resultados completamente diversos, a virtud de complicaciones políticas. Una porción considerable de cada uno de los partidos políticos, aquella que había tomado parte más activa en los negocios públicos de los últimos años, era esencialmente refractaria a una reforma constitucional seria, sobre todo en cuanto ella pudiera importar la supresión del régimen parlamentario, y una vez que el Presidente enderezó resueltamente el rumbo hacia la reforma, se prepararon para hacerla fracasar, o por lo menos para enervarla, en la futura Asamblea Constituyente. La discusión del procedimiento que debería adoptarse, perturbada entonces por las influencias políti. cas, se hizo interminable y accidentada remantando en el fracaso de la Sub-Comisión encargada de resolver ese punto.

Por el contrario, la otra, Sub-Comisión, la encargada de e.studiar sustantivamente la reforma constitucional, funcionó eon la debida regularidad, presidida por el señor Alessandri mismo y con la cooperación del Ministro de Justicia e Instrucción Pública, don José Maza. Actuaron como secretarios, el Sub-Secretario del Ministerio del Interior, don Edecio Torreblanca, en la mayor parte de las sesiones, y en dos de sllas el Secretario Privado del Presidente, abogado don Fernando Alessandri. Esta Sub-Comisión preparó el proyecto de reforma constitucional, en un ambiente de patriótica armonía, en la eual no hubo seguramente uno solo de sus miembros que no sacrificara alguna parté de sus convicciones a trueque de realizar una obra de conciliación con la mayor rapidez posible. El trabajo qúedó terminado y revisado en treinta sesiones celebradas entre el 18 de Abril y el 13 de Julio de 1925.

15.-Terminado en la Sub-Comisión el proyecto de reforma, en la $30{ }^{a}$ sesión de 13 de Julio de 1925 , fué sometido al examen cle la Gran Comisión Consultiva que celebró dos sesiones 
el 22 y el 23 de Julio. En esas sesiones se formularon numerosas indicaciones para modificar el proyecto, $\mathbf{y}$ de dos partidos políticos opuestos partieron ataques á fondo contra él e indicaciones de considerable entidad encaminadas at mantenimiento integral o ligeramente suavizado del sistema parlamentario, que habrían hecho fracasar el proyecto si éste no hubiera sido tan enérgica y hábilmente defendido por el Presidente Alessandri. El resultado fué la aprobación en general del proyecto, y su devolución a la Sub-Comisión para que ésta examinara las numerosas indicaciones formuladas en la Gran Comisión y diera la última mano al trabajo.'

La Sub-Comisión desempeñô este cometido, celebrando tres sesiones más y dando término definitivo a su labor en la sesión. 33." del 3 de Agosto de 1925. El personal que asistió a estas tres últimas sesiones fué muy reducido, porque algunos de los políticos que anterionmente habían cooperado con decisión a la preparación del proyecto de reforma, después de la reunión de la Gran Comisión, optaron por restar su cooperación a la Sub-Comisión. También faltó el autor de este libro, pero no por antipatía al proyecto, que aprobaba de todo corazón, sino por haber tenido que partir al norte como miembro del Comité Jurídico de la Comisión Plebiscitaria de Tacna $\mathrm{y}$ Arica.

La cuestión relativa al modus como debiera ser aprobada la nueva Constitución, fué hábilmente resuelta por el Presidente Alessandri. Dos órdenes de consideraciones concurrían a hàcer impracticable la convocatoria a una Asamblea Constituyente. En primer lugar, la manifiesta mala voluntad de dos partidos políticos para toda reforma que importara la supresión de sus regalías parlamentarias, permitía esperar que las diseusiones de una Asamblea Constituyente se prolongarían en forma indefinida, para arribar talvez a resulitados negativos o contraproducentes. En segundo lugar, terminada la preparación del proyecto de reforma a principios de Agosto, y debiendo concluir el 23 de Diciembre el período presidencial del señor Alessandri, sólo quedaba un lapso de tiempo de poco menos de cinco meses para realizar la elección de la Asamblea con la consiguiente calificación de las elecciones de sus miembros, en seguida la discusión del proyecto constitucional, y después las elecciones del nuevo Presidente de la República y del nuevo Congreso, y las calificaciones respectivas. 
En tan difícil-como apremiante situación, el Presidente Alessandri optó por recurrir directamente al veredicto popular, convocando a los cindadanos inseritos en los Registros Elerctorales formados en Noviembre de 1924 con el máximum de corrección, a un plebiscito que debía tener lugar el día 30 de Agosto, y en el cual los ciudadanos debían pronunciarse por medio de cédulas de los tres colores de la bandera nacional, en uno de tres sentidos: la cédula roja importaría la aprobación del proyecto de nueva Constitución elaborado por la Sub-Comisión; la cédula azul la aprobación de las modificaciones de tendencia parlamentarista propuestas por algunos políticos en la Gran Comisión; y finalmente la cédula blan. ca, importaría el rechazo de las dos proposiciones anteriores.

El pueblo chileno aprobó en el Plebiscito verificado el 30 de Agosto de 1925, el texto constitucional elaborado por la Sub-Comisión Reformadora y patrocinado por el Presidente Alessandri, que es hoy la Constitución de la República. 


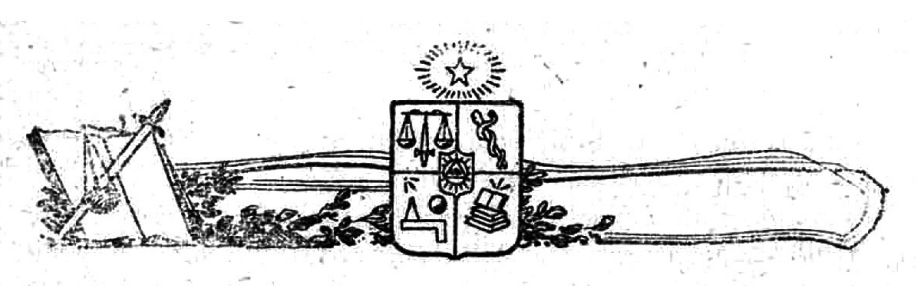

\section{APÉNDICE}

\section{División de la tierra en Chile}

Por constiderarlos de sumo interés, insertamos al final de nuestra obra, algunos datos relativos a los latifundios de Chile, que debemos a la amablie cooperación de nuestro estimado amigo el señor Diputado don Héctor Alvarez, quien, con natriótica constancia, ha acopiado una abundante información de fuentes oficiales, enteramente fidedignas, relativa a la extensión $\mathrm{y}$ aprovechamiento de las tierras cultivables de nuestro país.

Agradecemos cordialmente la cooperación de nuestro estimable amigo, y hacemos votos muy flervientes en el sentido de que pueda él disponer del tiempo y los medios necesarios para exponier sus datos en un libro que vengat a ilustrar la conciencia pública en la importante materia a que ha consagrado su investigación.

Chile, con una superficie geográfica de $75.151,500$ hectáreas, tiene 49.726,056 hectáreas perdidas en desiertos, montañas y tierras estériles, y sólo 25.287,133 hectáreas de terrenos aprovechables en la agricultura, o sea, el $33,6 \%$ del total, extensiôn susceptible de ser aumentaida en $3.000,000$ de hectáreas mediante la ejecución de abras de riego en las provincias del norte, $\mathrm{y}$ en $6.000,000$ más, por el diesmonte y colonización de tierras australes. Es dable esperar, en consecuencia, que el 
área cultivable de la República pueda alcanzar, a grian costo, a la mitad del territorio nacional.

De los 25.287,133 de hectáreas actualmente cultivables, $15.813,796$ corresponden a 570 latifundios de más de 5000 hectáreas, o sea, el $62,19 \%$. Hay también 2080 propiedades entre 1000 y 5000 hectáreas, que, a nuestro juicio, también deben ser consideradas latifundios, con una extensión total de $4.245,124$ hectáreas, o sea el $16,70 \%$ det total. Por consiguiente, $20.258,920$ hectáreas, o sea el $78,89 \%$ del terreno cultiviable del país corresponden a sólo 2650 propiedades.

A la pequeña y mediana propiedad, estimanło como tales las inferiores a 1000 hectáreas, corresponden a $4.928,213$ hectáreas, distribuidas entre 107,551 propietarios.

Estas cifras no se pueden tomar como absolutamente precisas, dadis la imperfeceión de nuestro sistema catastral, pero arrojan luz suficiente para calcular que las cuatro quintas partes del terreno cultivable corresponden a los latifundios y sólo un quinto a la propiedad mediana y peciueña.

Estimando en $4.000,000$ de habitantes la población de la República (que en realidad debe subir de seis millones), tendríamos que los latifundios de más de mil hectáreas están en manos de $0,64 \%$ de la población. Todavía es de notar que los latifundios de más de 5000 hectáreas, corresponden a sólo 570 personas, o sea, menos del $1 \frac{1}{2} \%$ oos de la población.

Según los datos dial señor Alvarez, sólo el 2,6\% de los habitantes de Chile tienen propiedades de suelo cultivable, y sólo se cultivan en realidad los dos quintos del área aprovechable actualmente.

Sea cual fuere la imperfeceión de las estadísticas oficiales que ha tenido a la vista eil señor Alvarez, queda demostrada con bastante aproximación la magnitud de la mala distribución de la tierra cultivable en un país eomo el nuestro, que siendo pequeño en comparación con las grandes extensiones territoriales del Brasil, República Argentina, Bolivia y el Perú, necesita remediar a la brevedad posible, el mal, para no quedar más rezagado de lo que está en el movimiento económico del Continante, y aproximarse al ideal de una verdadera demoeracia, indispensable para el correcto funcionamiento del sistema republicano de gobierno.

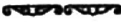


